\title{
SOLUSI HAMPIRAN PERSAMAAN LOGISTIK NON-AUTONOMOUS
}

\author{
Mohamad Riyadi ${ }^{1)}$ dan Daswa) \\ 1) Program Studi Pendidikan Matematika, FKIP, Universitas Kuningan, Indonesia; \\ mohamad.riyadi@uniku.ac.id \\ ${ }^{2)}$ Program Studi Teknik Informatika, FKOM, Universitas Kuningan, Indonesia; \\ daswa@uniku.ac.id
}

\begin{abstract}
The aim of this study is to derive the approximation solution of the nonautonomous logistic equation with a non-constant carrying capacity. The solution is found via predictor-corrector method (Adams-Bashforth-Moulton method, Milne method and Hamming method). The approximation solution that obtained, then, is compared to the exact solution. The results show that, for small step size, the approximation solution approximate the exact solution is in good agreement.
\end{abstract}

Keywords: Logistic equation, Non-autonomous, Carrying capacity, Predictor-corrector Method

\begin{abstract}
ABSTRAK
Studi ini membahas solusi hampiran untuk persamaan logistik non-autonomous dengan carrying capacity tak konstan. Solusi dihitung dengan menggunakan metode Predictor - Corrector (metode Adams-Bashforth-Moulton, metode Milne dan metode Hamming). Solusi hampiran yang diperoleh, kemudian, dibandingkan dengan solusi eksak. Hasil menunjukkan bahwa untuk jumlah langkah yang banyak, solusi hampiran mengaproksimasi solusi eksak dengan kecocokan yang baik.
\end{abstract}

Kata Kunci: Persamaan logistik, Non-autonomous, Carrying capacity, Metode predictor-corrector

\section{PENDAHULUAN}

Suatu fenomena atau sistem dalam kehidupan sehari-hari, seperti dalam bidang ekologi, dalam mempelajarinya sering digunakan dalam bentuk matematika. bentuk matematika dari suatu fenomena dikenal sebagai model matematika dan dibangun untuk tujuan tertentu. sebagai contoh, untuk memahami mekanisme suatu ekosistem yaitu dengan mempelajari pertumbuhan suatu populasi dalam sistem tersebut.

pemodelan matematika yang dibangun untuk menggambarkan fenomena pertumbuhan populasi misalnya, sering menggunakan fungsi-fungsi atau persamaan yang tidak sederhana. solusi untuk persamaan yang lebih kompleks terkadang sulit bahkan tidak mungkin diperoleh secara eksak. maka dari itu, 
solusi numerik digunakan untuk mengaproksimasi solusi eksak dari persamaan tersebut.

salah satu contoh persamaan yang populasi adalah persamaan logistik (atau verhulst) yang merupakan persamaan diferensial linear orde satu (Murray, 2002) yaitu mempelajari fenomena pertumbuhan

$$
\begin{gathered}
\frac{d N(t)}{d t}=a N(t)\left(1-\frac{N(t)}{K}\right), \\
N(0)=N_{0}
\end{gathered}
$$

dimana $N(t)$ menyatakan densitas populasi, $a$ adalah tingkat pertumbuhan instrinsik, $k$ adalah carrying capacity lingkungan dan $N_{0}$ adalah densitas populasi saat waktu $t=0$. Karena $a$ dan $k$ konstan, maka persamaan logistik

$$
N(t)=\frac{K N_{0}}{K e^{a t}+N_{0}\left(1-e^{-a t}\right)}
$$

Carrying capacity $k$ di pers. (1) yang bernilai konstan adalah sering tidak realistik (Safuan, Jovanoski, Towers, \& Sidhu, 2013). Maka, sebuah alternatif untuk nilai carrying capacity yang konstan digunakan sebuah carrying capacity yang bergantung waktu, $K(t)$, untuk penerapan yang bervariasi. Dengan menggunakan carrying capacity yang bergantung waktu, $K(t)$, yang eksplisit mengubah

$$
\frac{d N(t)}{d t}=a N(t)\left(1-\frac{N(t)}{K(t)}\right)
$$

dengan carrying capacity

$$
K(t)=K_{S}\left(1-b e^{-c t}\right),
$$

di sini, $K_{s}$ adalah level saturasi bakteria, $c$ adalah konstanta saturasi, $b=1-$

$K_{0} / K_{s}$ dengan $K(0)=K_{0}$ dan $0<b<$ 1.

Solusi eksak untuk pers. (3) - (4) adalah

$$
N(t)=\frac{N_{0} e^{a t}}{1+\frac{a N_{0}}{K_{s}} \int_{0}^{t} \frac{e^{a x}}{1-b e^{-c x}} d x}
$$


dengan bagian integral diusulkan menggunakan pendekatan deret (Safuan et al., 2013). Dalam aplikasinya, saat menghitung $N(t)$, bagian integral yang dihitung menggunakan deret terdapat pemotongan suku. Artinya solusi yang dihasilkan tidak diperoleh secara eksak.

Salah satu metode untuk mencari solusi hampiran untuk pers. (3) - (4) adalah metode Predictor Corrector. Berbeda dengan metode satu-langkah yang hanya menggunakan satu titik sebelumnya, metode ini menggunakan beberapa titik sebelumnya untuk perhitungan. Namun demikian, metode ini, yang menggunakan kombinasi predictor dan

$$
y^{\prime}=f(t, y), \quad y\left(t_{0}\right)=y_{0}
$$

dikatakan masalah nilai awal. Solusi masalah nilai awal (6) pada suatu selang $\left[t_{0}, b\right]$ adalah fungsi yang terdiferensialkan $y=y(t)$ sehingga $y\left(t_{0}\right)=y_{0}$ dan $y^{\prime}(t)=f(t, y(t))$ untuk semua $t \in\left[t_{0}, b\right]$. Dalam banyak aplikasi, solusi $y=y(t)$ tidak mudah diperoleh secara eksak. Maka digunakan metode numerik untuk menentukan solusi hampiran pada masalah nilai awal (6).

Metode numerik yang dapat digunakan adalah metode single-step dan metode multi-step. Metode singlestep menggunakan hanya satu informasi dari titik sebelumnya untuk menghitung titik berturut-turut selanjutnya. Yaitu, hanya titik awal $\left(t_{0}, y_{0}\right)$ yang

$$
y\left(t_{k+1}\right)=y\left(t_{k}\right)+\int_{t_{k}}^{t_{k+1}} f(t, y(t)) d t
$$

Predictor menggunakan hampiran polinomial Lagrange untuk $f(t, y(t))$ berdasarkan pada titik-titik $\left(t_{k-3}, f_{k-3}\right)$, $\left(t_{k-2}, f_{k-2}\right),\left(t_{k-1}, f_{k-1}\right)$ dan $\left(t_{k}, f_{k}\right)$.
Hampiran polinomial tersebut diintegrasikan pada selang $\left[t_{k}, t_{k+1}\right]$ pada pers. (7), sehingga diperoleh predictor Adams-Bashforth 


$$
p_{k+1}=y_{k}+\frac{h}{24}\left(-9 f_{k-3}+37 f_{k-2}-59 f_{k-1}+55 f_{k}\right)
$$

corrector dapat dikembangkan. Sekarang nilai $\$ p_{k+1}$ dapat digunakan. Polinomial Lagrange kedua untuk $f(t, y(t))$ dibangun berdasarkan pada titik-titik $\left(t_{k-2}, f_{k-2}\right),\left(t_{k-1}, f_{k-1}\right)$ dan

$$
y_{k+1}=y_{k}+\frac{h}{24}\left(f_{k-2}-5 f_{k-1}+19 f_{k}+9 f_{k+1}\right)
$$

Aspek umum pada metode ABM (Hoffman \& Frankel, 2001)

4. formula konvergen karena konsisten dan conditionally stable. $\left(t_{k+1}, f\left(t_{k+1}, p_{k+1}\right)\right)$. Polinomial kedua tersebut diintegrasikan pada selang $\left[t_{k}, t_{k+1}\right]$, sehingga diperoleh corrector Adams-Moulton

adalah

1. formula berbentuk implisit dan memerlukan satu evaluasi fungsi turunan tiap langkah

2. formula konsisten, $O\left(h^{5}\right)$ secara lokal dan $O\left(h^{4}\right)$ secara global.

3. formula conditionally stable.

$\left(t_{k}, f_{k}\right)$ dan titik baru $\left(t_{k+1}, f_{k+1}\right)=$

$$
y\left(t_{k+1}\right)=y\left(t_{k-3}\right)+\int_{t_{k-3}}^{t_{k+1}} f(t, y(t)) d t
$$

Predictor menggunakan hampiran polinomial lagrange untuk $f(t, y(t))$ berdasarkan pada titik-titik $\left(t_{k-2}, f_{k-2}\right),\left(t_{k-1}, f_{k-1}\right)$ dan $\left(t_{k}, f_{k}\right)$.

$$
p_{k+1}=y_{k-3}+\frac{4 h}{3}\left(2 f_{k-2}-f_{k-1}+2 f_{k}\right)
$$

Corrector dapat dikembangkan dengan cara yang sama. Sekarang nilai $p_{k+1}$ dapat digunakan. Polinomial Lagrange kedua untuk $f(t, y(t))$ dibangun berdasarkan pada titik-titik $\left(t_{k-1}, f_{k-1}\right)$,

$\left(t_{k}, f_{k}\right)$ dan titik baru $\left(t_{k+1}, f_{k+1}\right)=$ $\left(t_{k+1}, f\left(t_{k+1}, p_{k+1}\right)\right)$. Polinomial kedua tersebut diintegrasikan pada selang $\left[t_{k-1}, t_{k+1}\right]$, sehingga diperoleh corrector Milne yaitu

$$
y_{k+1}=y_{k-1}+\frac{h}{3}\left(f_{k-1}+4 f_{k}+f_{k+1}\right)
$$

\section{Metode Hamming}

Metode Milne merupakan metode yang tidak stabil, walaupun tidak selalu terjadi. Ketidakstabilan metode tersebut karena correctornya (Chapra et al., 2010). Alternatif lain agar memperbaiki kekurangan ini dengan mengembangkan correctornya. Umumnya corrector yang digunakan adalah corrector Hamming. 
Predictor dan corrector untuk metode Hamming adalah

$$
\begin{gathered}
p_{k+1}=y_{k-3}+\frac{4 h}{3}\left(2 f_{k-2}-f_{k-1}+2 f_{k}\right) \\
y_{k+1}=\frac{-y_{k-2}+9 y_{k}}{8}+\frac{3 h}{8}\left(-f_{k-1}+2 f_{k}+f_{k+1}\right)
\end{gathered}
$$

(Hamming, 1959).

\section{METODE DAN DESAIN PENELITIAN}

Pada studi ini, akan dihitung solusi hampiran untuk persamaan logistik non-autonomous dengan carrying capacity tak konstan yaitu pers. (3)-(4). Solusi hampiran dihitung dengan menggunakan metode Predictor - Corrector. Algoritma metode ini kemudian disusun dan diimplementasikan dengan bantuan Matlab (Mathews, 1992; Mathews, Fink, \& others, 2004). Hasil solusi hampiran akan dibandingkan dengan solusi eksak pada pers. (5) dengan meninjau grafik dan galatnya.

\section{SOLUSI HAMPIRAN}

1. Algoritma

Algoritma untuk menghitung solusi hampiran pers. (3) - (4) yaitu

* input data

* hitung solusi hampiran dengan metode ABM

* hitung solusi hampiran dengan metode Milne

* hitung solusi hampiran dengan metode Hamming
* hitung solusi eksak

* plot solusi hampiran dan solusi eksak

* hitung error

* plot error dari solusi hampiran

* hitung error relatif

* plot error relatif dari solusi hampiran

2. Simulasi

Simulasi pada metode Predictor Corrector harus memperhatikan ukuran langkah atau banyaknya langkah. Jika ukuran langkah terlalu besar ( $h$ besar), yaitu banyaknya/jumlahnya langkah kecil/sedikit, metode Predictor Corrector akan tidak stabil. Saat ukuran langkah terlalu besar ( $h$ besar) pada selang yang besar, hasil tidak stabil dan terkadang akan menghasilkan perhitungan yang berosilasi.

Berikut hasil simulasi yang dilakukan untuk jumlah langkah, $N=45$ dan $N=70$ dengan menggunakan parameter yaitu $a=$ 6,6/hari, $b=0,99996, c=1,9 /$ hari, $N_{0} \approx K_{0}=920 / \mathrm{cm}^{2}$ dan $\quad \$ K_{s}=$ $2,3 \times 10^{7} / \mathrm{cm}^{2}$. 


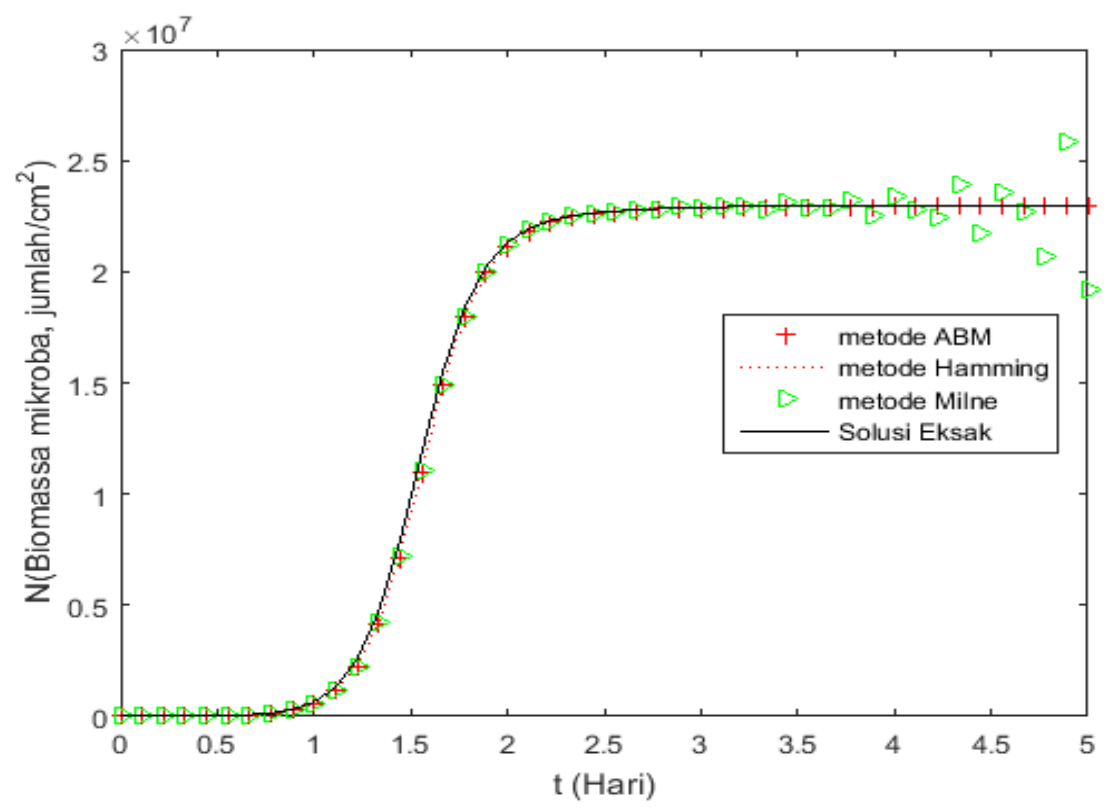

Gambar 1. Solusi Hampira vs Eksak untuk N = 45

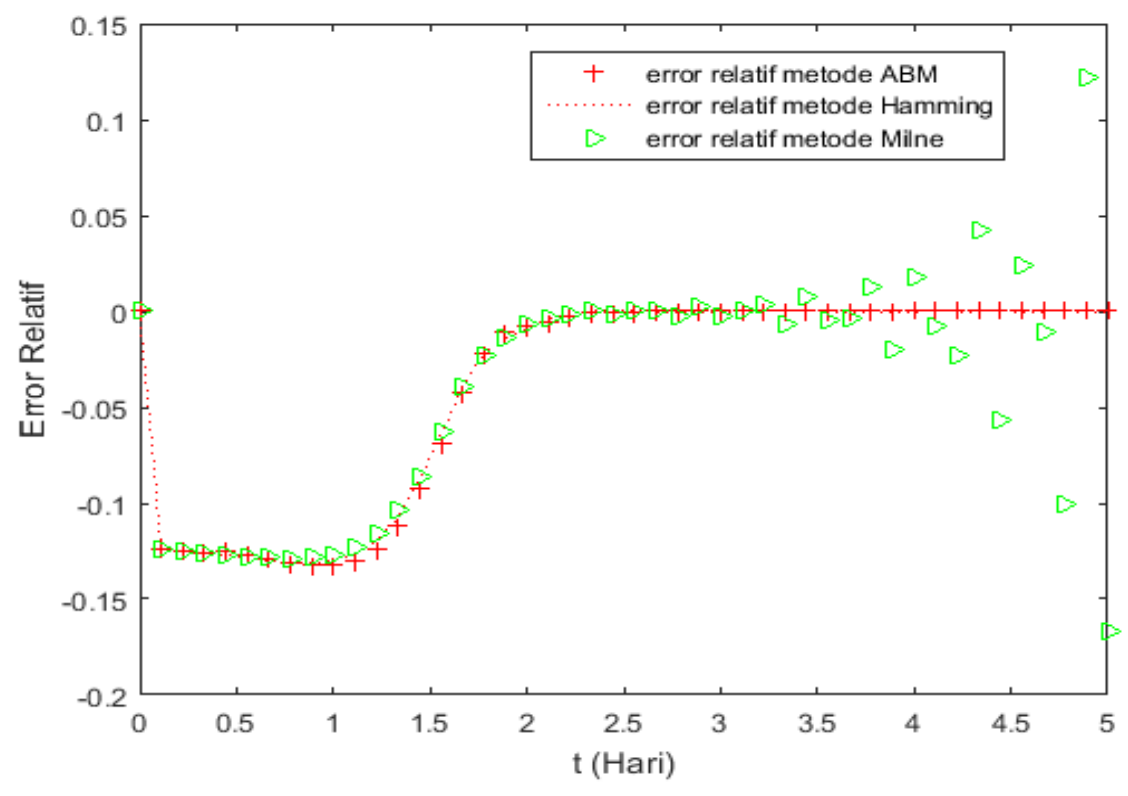

Gambar 2. Error Relatif Solusi Hampiran untuk $N=45$

Untuk simulasi dengan $N=45$, grafik solusi hampiran masing-masing metode dan solusi eksak ditunjukkan pada gambar 1, sedangkan error relatif ditunjukkan pada gambar 2.

Metode ABM dan metode Hamming menghasilkan solusi hampiran yang mendekati solusi eksak dengan kecocokan yang baik (gambar
1). Kecuali metode Milne yang divergen saat $t \rightarrow 5$, yang mana solusi hampiran yang diperoleh berosilasi menjauhi solusi eksak. Untuk error relatif, telah dilakukan simulasi untuk menghitung solusi hampiran persamaan logistik non-autonomous, yaitu persamaan logistik dengan carrying capacity tak konstan. Metode Predictor - Corrector digunakan untuk 
menghitung solusi hampiran tersebut. Hasil menunjukkan bahwa untuk jumlah langkah yang banyak, solusi yang dihasilkan oleh metode-metode Milne menunjukkan hasil yang baik pada paruh waktu pertama. Namun setelah itu tampak grafik berosilasi. Metode ABM dan Hamming metode tampak lebih stabil (gambar 2).

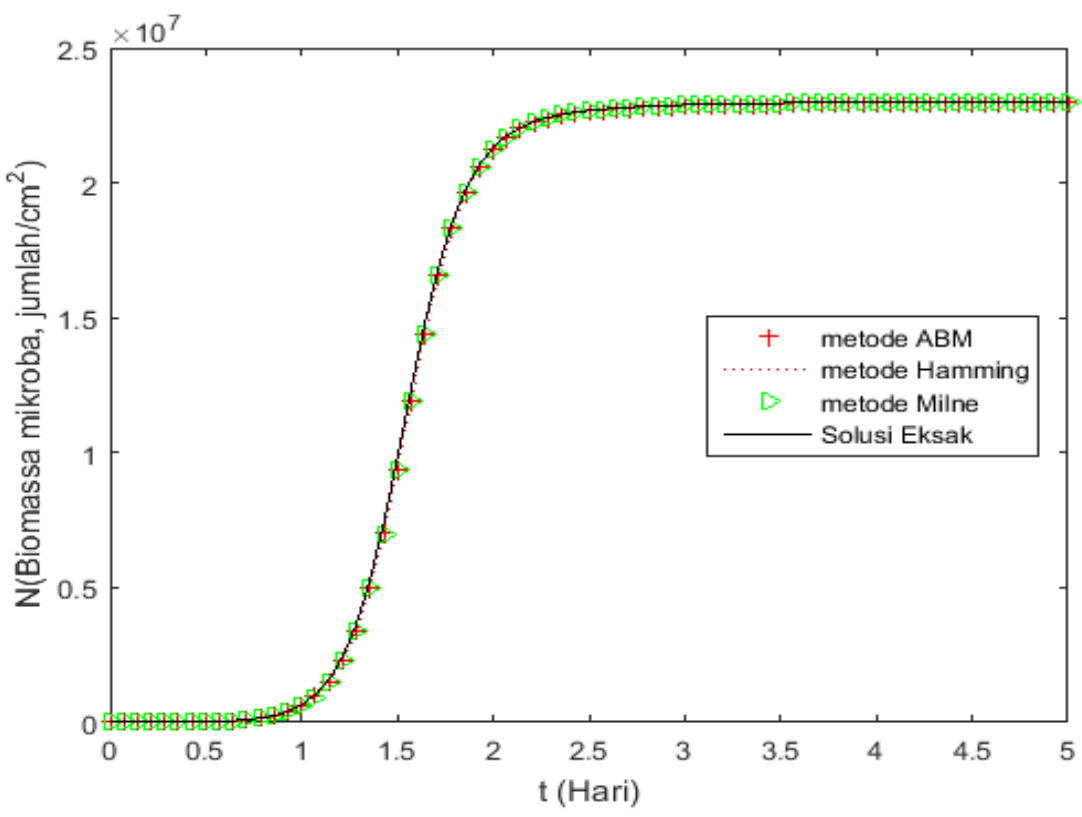

Gambar 3. Solusi Hampiran VS Eksak untuk $\mathbf{N}=70$

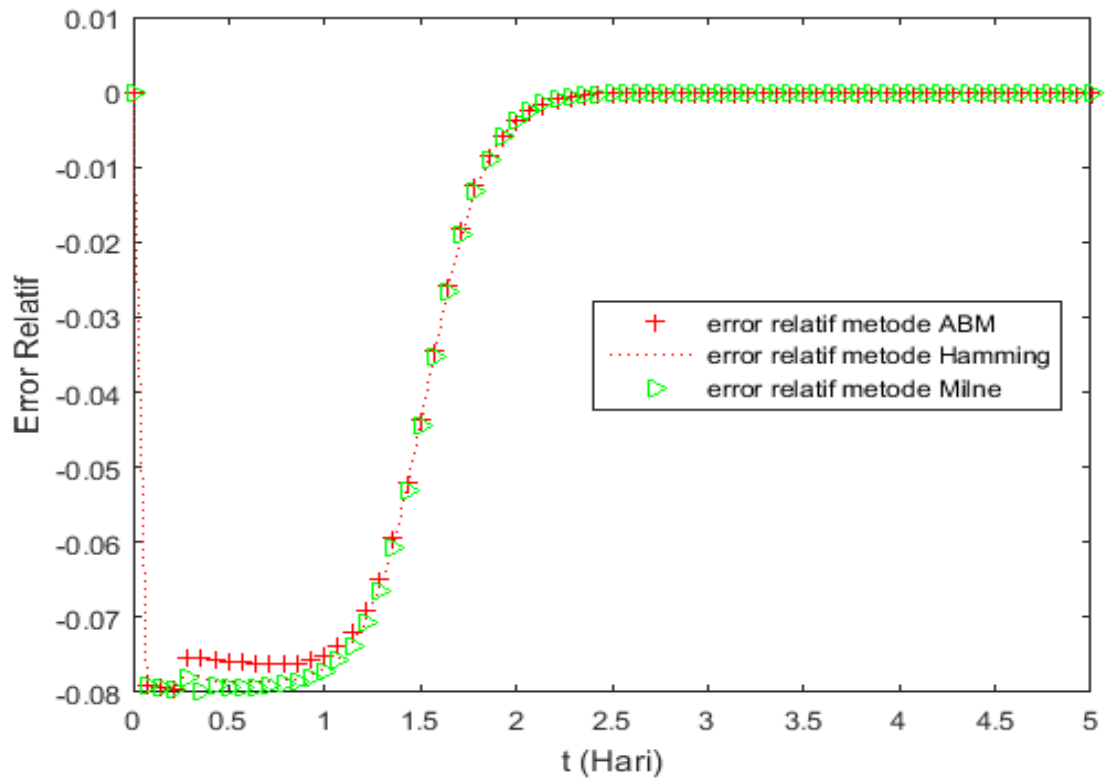

Gambar 4. Error Relatif Solusi Hampiran untuk $\mathbf{N}=\mathbf{7 0}$

Untuk simulasi dengan $N=t \rightarrow 5$ (gambar 3). Ketiga metode 70, tampak semua metode Predictor - Corrector menghasilkan menghasilkan solusi yang stabil saat 
solusi hampiran yang mendekati solusi eksak dengan kecocokan yang baik.

Dari gambar 3 dan 4, metode ABM merupakan metode yang lebih baik. Ini dilihat dari error relatif yang dihasilkan. Error relatif dari metode ABM lebih kecil dari metode lainnya.

\section{KESIMPULAN}

Telah dilakukan simulasi untuk menghitung solusi hampiran persamaan logistik non-autonomous, yaitu persamaan logistik dengan carrying capacity tak konstan. Metode Predictor - Corrector digunakan untuk menghitung solusi hampiran tersebut. Hasil menunjukkan bahwa untuk jumlah langkah yang banyak, solusi yang dihasilkan oleh metode ABM, metode Hamming dan metode Milne mengapproksimasi solusi eksak dengan kecocokan yang baik.

Untuk penelitian berikutnya, perlu dikaji batasan jumlah langkah yang tepat agar solusi hampiran stabil.

\section{DAFTAR PUSTAKA}

Boyce, W. E., \& DiPrima, R. C. (2012). Elementary Differential Equations and Boundary Value Problems, 10th Edition. Retrieved from https://books.google.co.id/books?i $\mathrm{d}=\mathrm{UzQcAAAAQBAJ}$
Chapra, S. C., Canale, R. P., \& others. (2010). Numerical methods for engineers. Boston: McGraw-Hill Higher Education.

Hamming, R. W. (1959). Stable predictor-corrector methods for ordinary differential equations. Journal of the ACM (JACM), 6(1), 37-47.

Hoffman, J. D., \& Frankel, S. (2001). Numerical methods for engineers and scientists. CRC press.

Mathews, J. H. (1992). Numerical methods for mathematics, science and engineering. Prentice-Hall.

Mathews, J. H., Fink, K. D., \& others. (2004). Numerical methods using MATLAB (Vol. 4). Pearson Prentice Hall Upper Saddle River, NJ.

Murray, J. D. (2002). Mathematical biology. I, volume 17 of Interdisciplinary Applied Mathematics. Springer-Verlag, New York.

Safuan, H. M., Jovanoski, Z., Towers, I. N., \& Sidhu, H. S. (2013). Exact solution of a non-autonomous logistic population model. Ecological Modelling, 251, 99102. 